ERJ

Engineering Research Journal

Faculty of Engineering

Minoufiya University

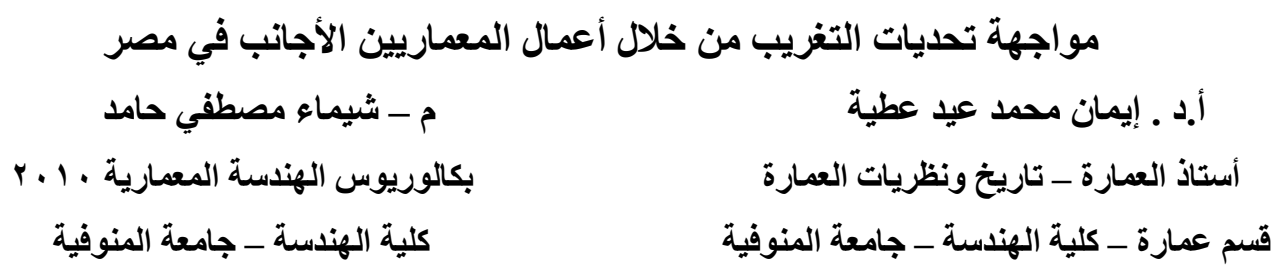

ملخص البحث:

العمارة هي الصورة الصـادقة والتعبير الحقيقي عن حضارة الإنسان، فهي الحياة التي تعيش في الماضي، وتعيش في الحاضر وستبقى في المستقبل،

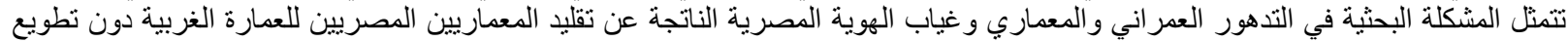

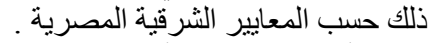
رصد أهم المعايير والأسس التصمية العميمية المعمارية المستنبطة من أعمال المعماريين الأجانب في مصر ومحاولة تطبيقها في ضوء الأوضاع

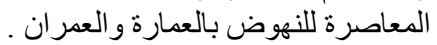

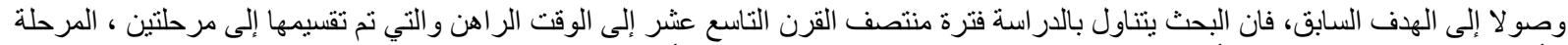

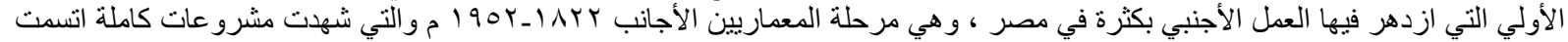

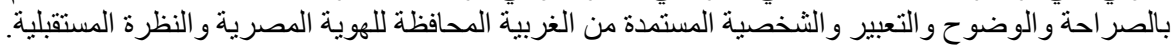

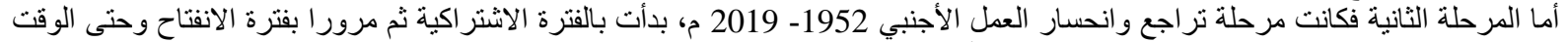

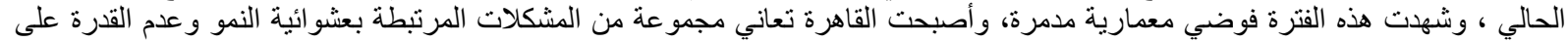
السيطرة عليه .

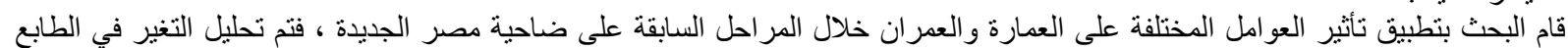
العمر اني والمعماري في الضاحية في سبيل الوصول إلى المعايير التي يمكن تطبيقها في الوقت الحالي للنهوض باليفة العمارة و العمر ان .

$$
\text { الكلمات الدالة : الطابع العمر اني و المعماري ـ الطر از ـ النسيج العمر اني ـ الهوية المصرية ـ انحسار . . }
$$

\title{
Abstract :
}

Architecture is the true image and true expression of human civilization, it is the life that lives in the past, and lives in the present and will remain in the future. The research problem is the urban and architectural deterioration and the absence of Egyptian identity resulting from the Egyptian architects tradition of Western architecture without adapting it according to the eastern Egyptian standards.Monitoring the most important architectural standards and foundations derived from the works of foreign architects in Egypt and trying to apply them in the light of contemporary conditions for the advancement of architecture and urbanism.

In order to reach the previous goal, the research deals with the study of the mid-nineteenth century to the present, which was divided into two phases, the first stage in which foreign work flourished heavily in Egypt, the stage of foreign architects $190 r_{-} 1 \wedge r$, which saw the full projects characterized by frankness and clarity and expression The character derived from the conservative Western of Egyptian identity and outlook.

The second phase was the stage of retreat and decline of foreign work 1952-2019, starting with the socialist period and then through the opening up to the present time, and this period has witnessed devastating architectural chaos, and Cairo is suffering from a series of problems related to the randomness of growth and the inability to control it.

The research applied the impact of various factors on architecture and urbanism during the previous stages on the suburb of Heliopolis, analyzing the change in the urban and architectural character in the suburb in order to reach the criteria that can be applied at the present time to promote architecture and urbanism. 
أ.د ـ إيمان محمد عيد عطية، م. شيماء مصطفي حامد "مواجهة تحديات التغريب من خلال أعمال المعماريين الأجاتب في مصر"

، اتسمت مشاريع المرحلة بالصراحة و والوضوح والتعبير و الثخصية المستمدة من الغربية المحافظة للهوية المصرية ولية ولئة والنظرة

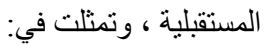

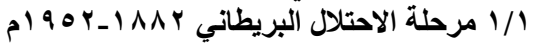

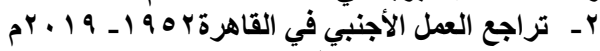

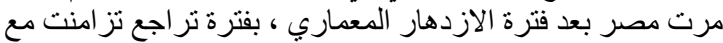

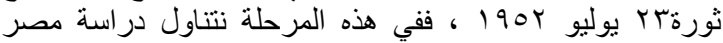

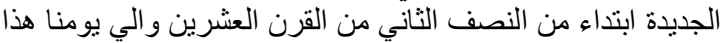

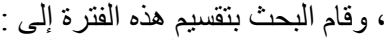

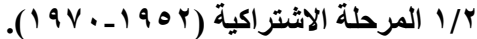

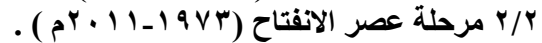

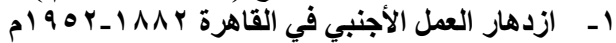

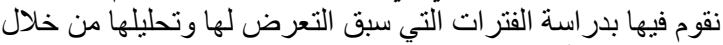

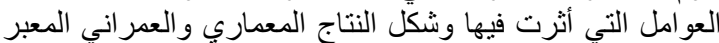

عن كل مرحلة.

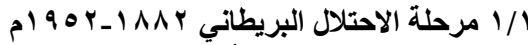

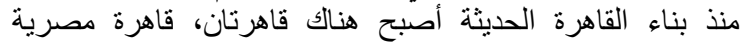
وأخري أوربية، ولم تكن توجد حدود مرئية بينة الفئن المدينة القديمة فاهنة والحديثة، وقد اتخذ التعمير في القاهرة الحديثة طابعاً استعمارياً، التحنة

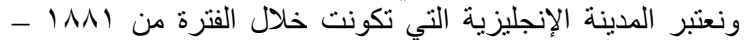

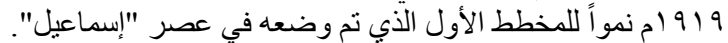

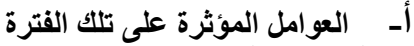

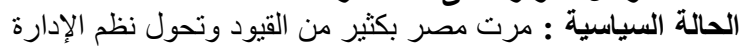

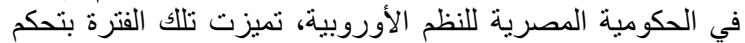

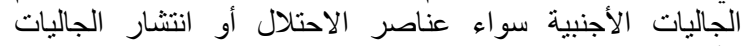

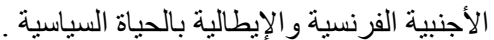

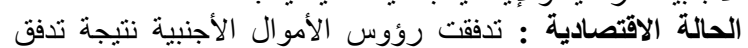

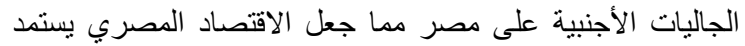

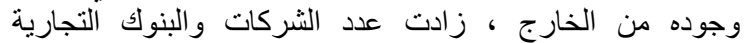
الأوروبية، الذي أدي بدوره ، زادي زئي زعادة رؤوس الأموال الأجنبية في الفية

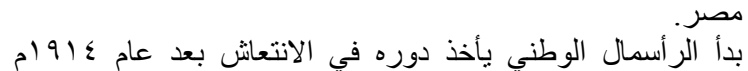

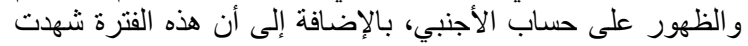

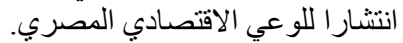

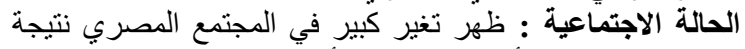

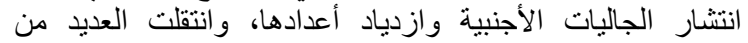

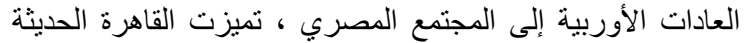

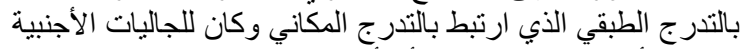

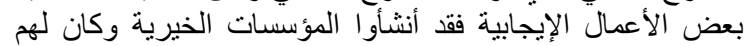

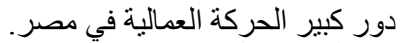

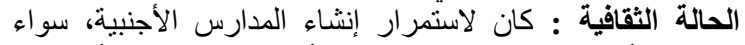

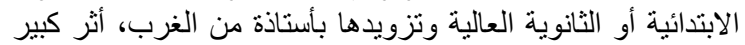

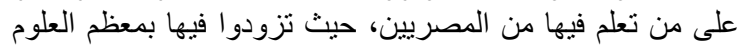

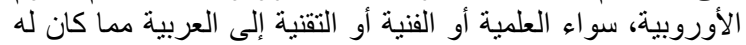

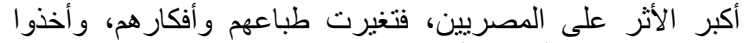
الكثير من طباع و أفكار الأوروبيين.

كل هذه العوامل كان لها الأثر في:

أصبحت العمارة انعكاساً لطرز المان المستعمرات الأوربية الفرنسية والإيطالية.

تدهورت عمارة و عمر ان القاهرة القديمة، ولكن ظهرت الإنه أحياء

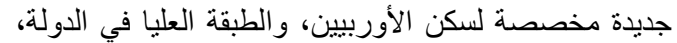

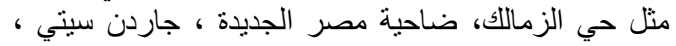
و غير هاً.

ب- تحليل الطابع العمراني خلال فترة ازدهار العمل الأجنبي

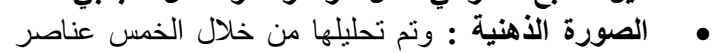

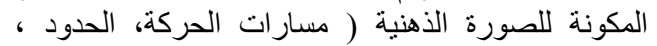

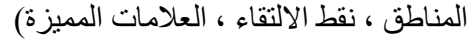
والتي يتم توضيحهم من خلال الخرائط التالية التحان
مقدمة

الهوية المصرية هي حالة تر اكمية من حضار ات وثقافات متعددة،

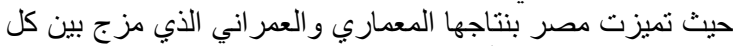

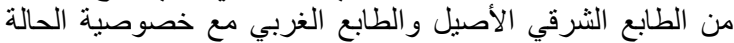

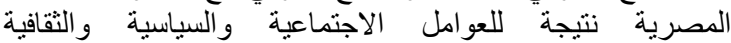

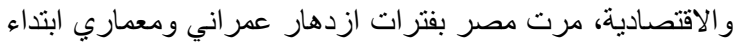

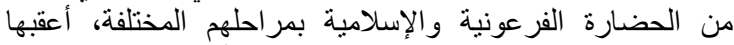

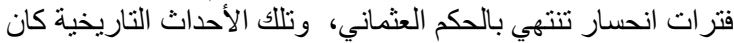

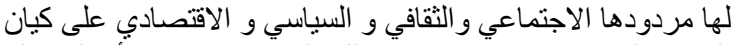

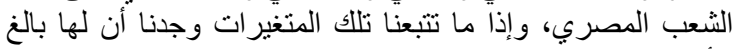

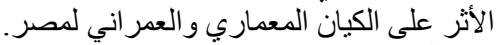

مشكلة البحث البك البكان

غياب الهوية الناتجة عن تقليد المعماريين المصريين للعمارة الغربية

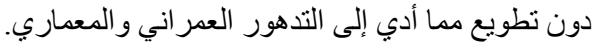

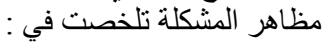

ظهور نتاج معماري يفتقد إلى الهوية المصرية وتسيطر عليه

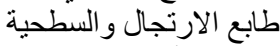
r. التقليد الأعمى للعمارة الغربية دونة درالية مراعاة للخصوصية

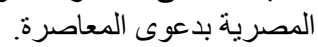

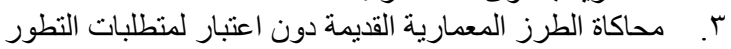

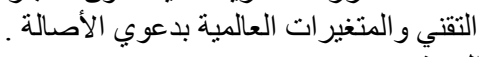

هدف البحث الثي

يتمثل الهدف الرئيسي للبحث استخلاص أهم المعايير المعمارية

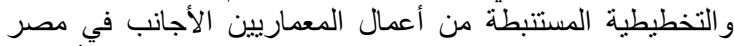

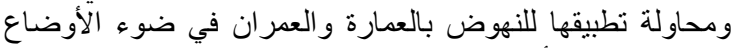

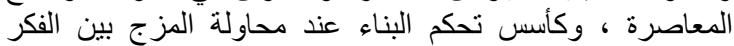
العربي والفكر الغربي سواء كانت بعقول وأيدي مصرية أو أبدي اليني

أجنبية .

منهجية البحث اعثن

اعتمد البحثث على البحث المنطقة ذات الطابع المميز والتي تم إنثائها في

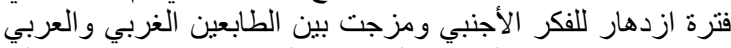

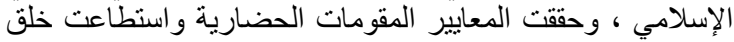

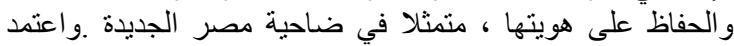

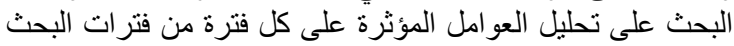

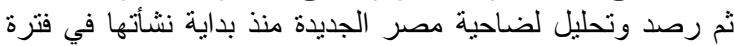

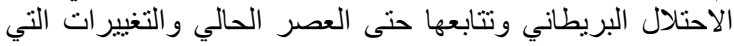

تمت فيها

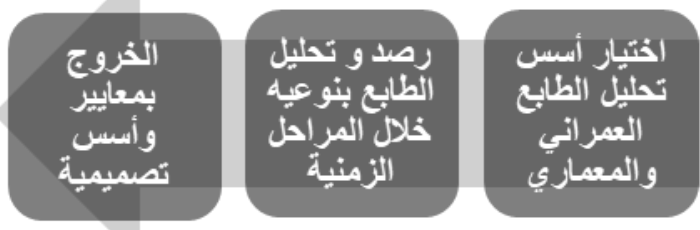

أهمية البحث

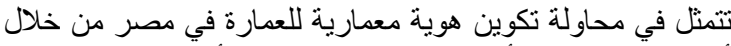

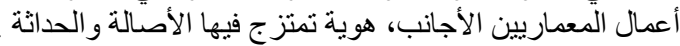

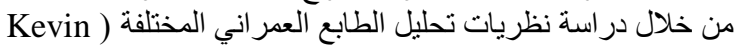
( Salingaros - Kropf - Spereiregen - Lynch

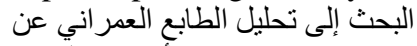

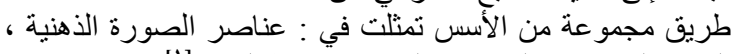

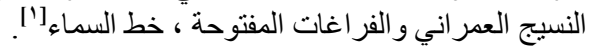

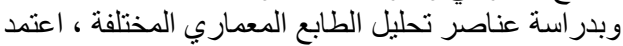

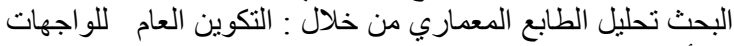

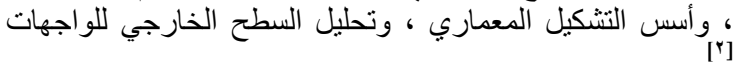

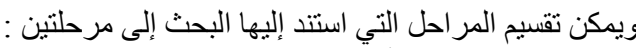

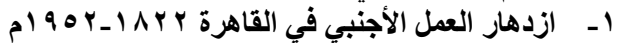

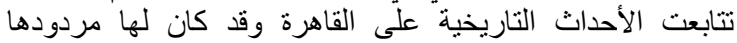
الاجتماعي و الثقافي والسياسي والاقتصادي على على كيان القاهرة عامة 
أ.د. ـ إيمان محمد عيد عطية، م. شيماء مصطفي حامد "مواجهة تحديات التغريب من خلال أعمال المعماريين الأجاتب في مصر"

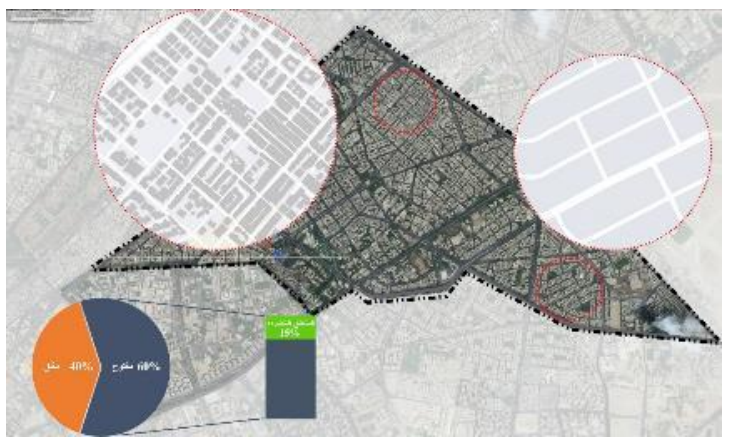

$$
\text { شكل ه النسيج العمر اني و الفراغات المفتوحة }
$$

خط السماء

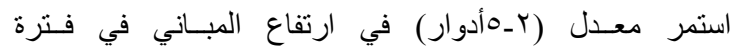

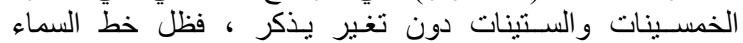
محتفظا بطابعه في هذه المرحلة .

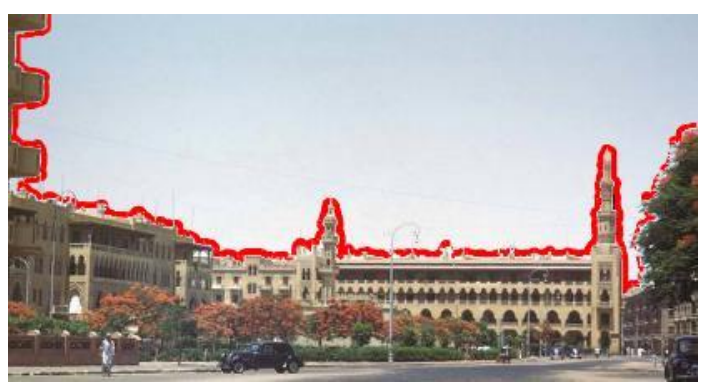

شكل 7 خط السماء لمرحلة الاشتر اكية المصدر : www.flicker.com

ج- تحليل الطابع المعماري خلال فترة الاشتر اكية

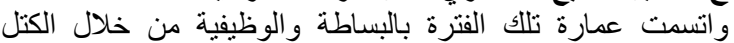

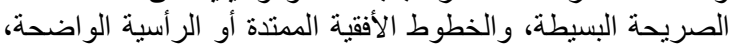

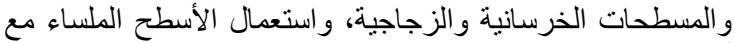

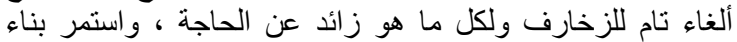
الفيلات على نطاق اقل من الفترة السابقة.

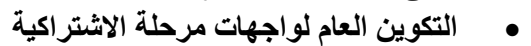

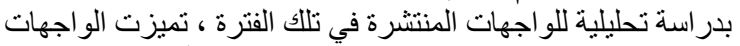

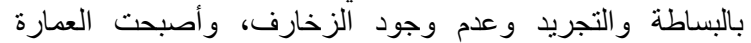
صندوقية ذات وحدات تكرارية

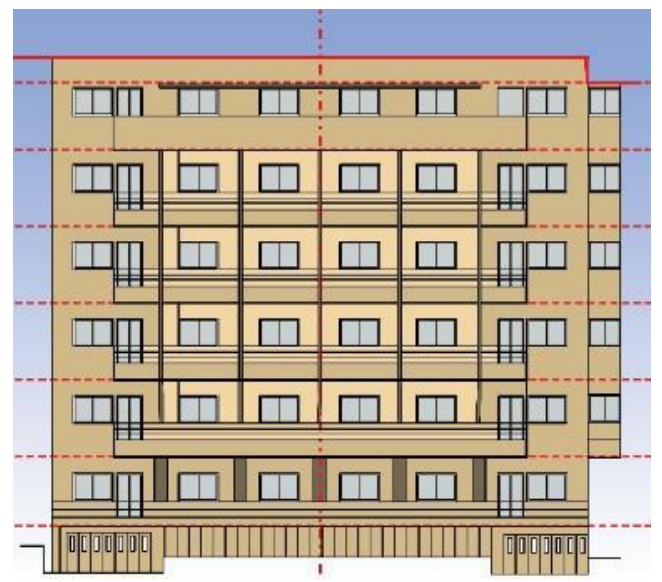

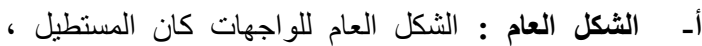

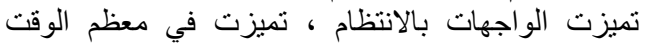

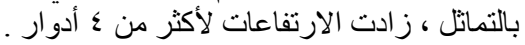

الحالة السياسية : توجهت الدولة نحو الاشتراكية، من خلال

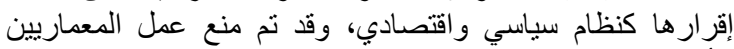

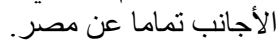
الحالة الاقتصادية :نجحت القيادة السياسية بإقامة صرح اثنتر اكي قوي، يهيمن على مقدرات الدولة ويتحكم في سياستها الإنة الداخلية

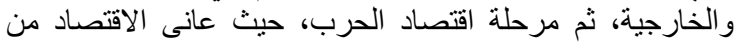

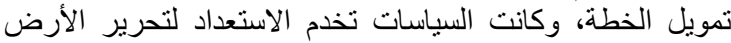
المصرية المحتلة. الحالة الاجتماعية : إعادة هيكلة شرائح المجتمع المصري، تحدئ المدرت

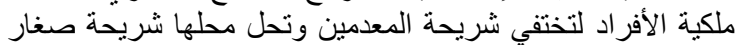

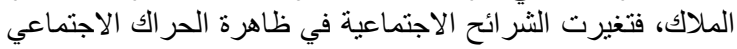

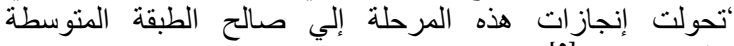

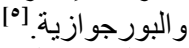
الحالة الثقافية : لقد تغير الوجه الثقافي للمجتمع المصري على إثر

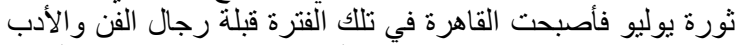

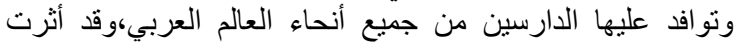

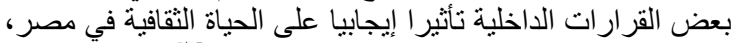

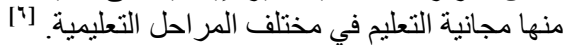
كل هذه العوامل كان لُها لها الأثر في:

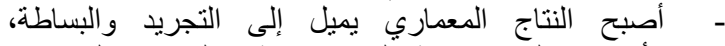

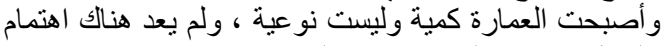

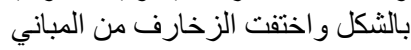

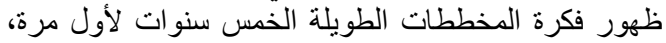
وبدء بالفعل وضع مخططات تنمية عمر انية في تلك الفئ الفترة.

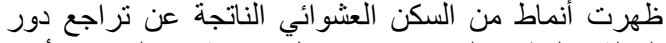

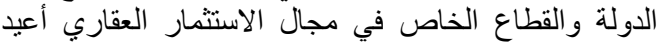

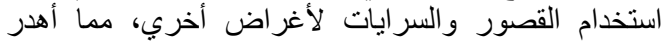
قيمتها الفنية و التاريخية. بـ تحليل الطابع العمراني خلال الاشتراكية

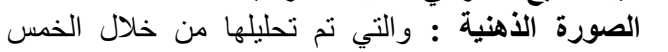

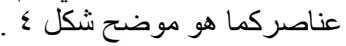
ألنسيج العمراني والمناطق المفتوحة :النسيج العمراني

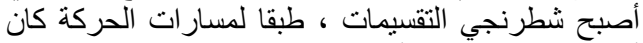

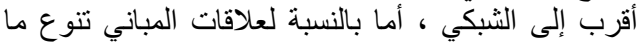

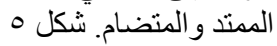

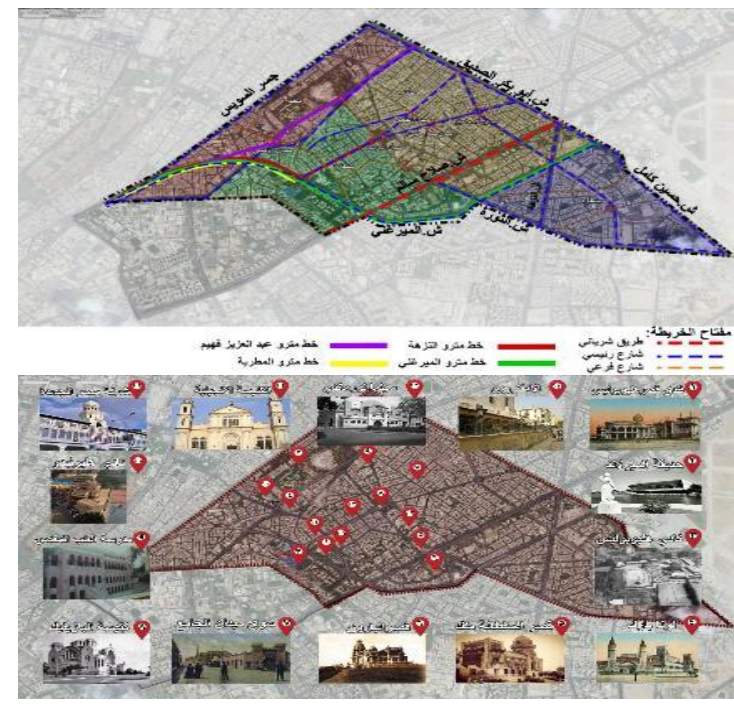

شكل ؛ خر ائط الصورة الذهنية لمرحلة الاحتلال البريطاني المصدر : تجميع الباحث 
أ.د ـ إيمان محمد عيد عطية، م. شيماء مصطفي حامد "مواجهة تحديات التغريب من خلال أعمال المعماريين الأجاتب في مصر"

الحالة الثقافية : اتسمت هذه الفترة بضعف عام في المناخ الفئ الثقافي

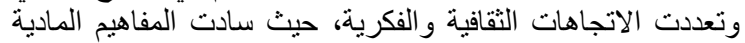

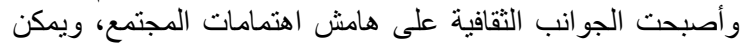

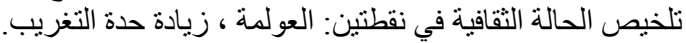

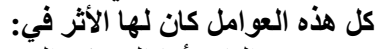

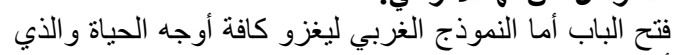

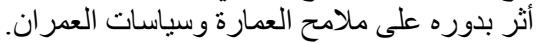

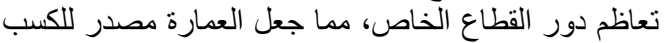

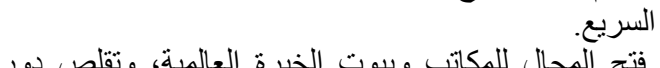

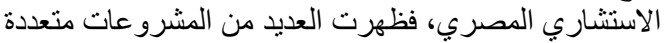

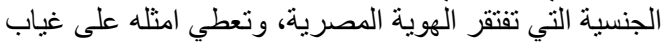

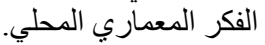

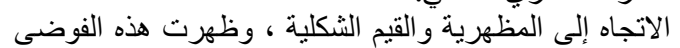

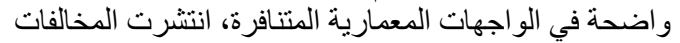
المعمارية و عدم تتفيذ القيم و المبادئ المعمارية المئية

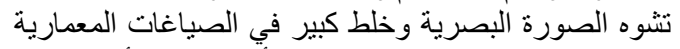
سواء على مستوي الفكر التصميمي أو التشكيلي أو المبيات المقياس أو المواد المستخدمة. المبن.

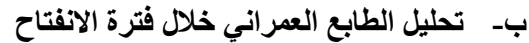
الصورة الذهنية : والتي تم تحليلها من خلال فرل الخمس عنداح عناصركما هو موضح شكل vورن

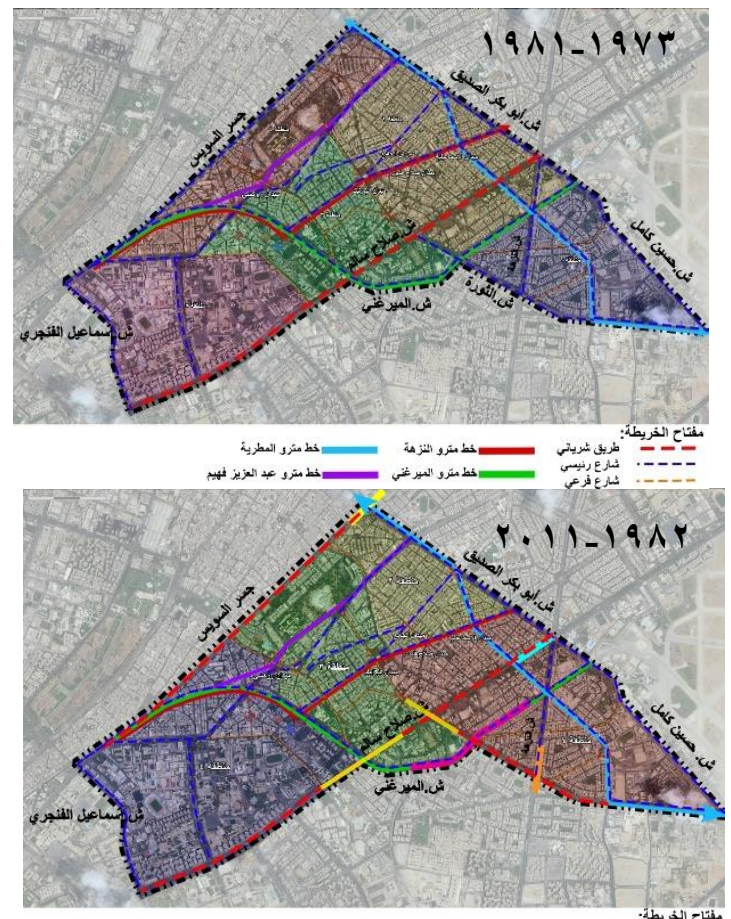

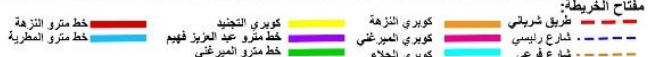

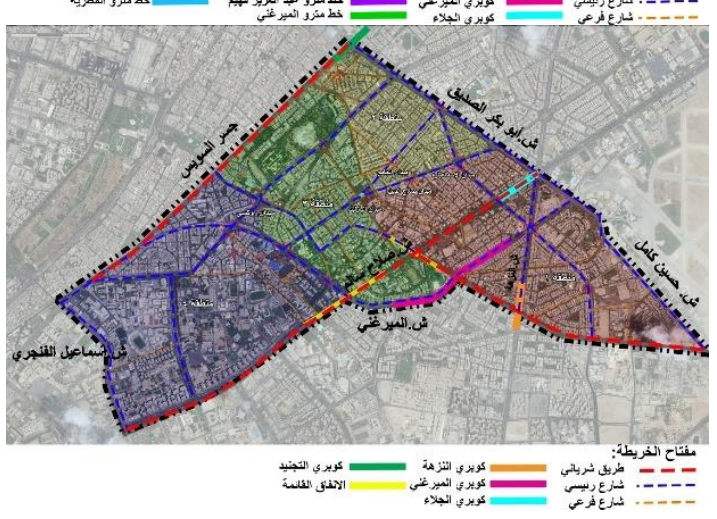

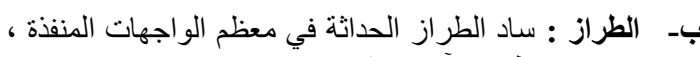

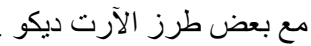

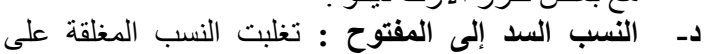

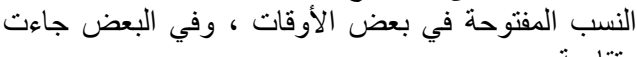

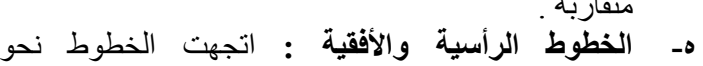

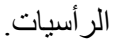

• التشكيل المعماري لواجهات مرحلة الاشتراكية

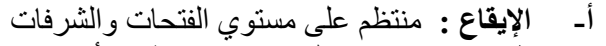

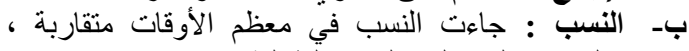

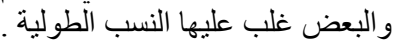

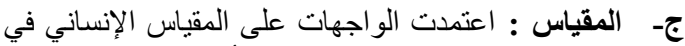

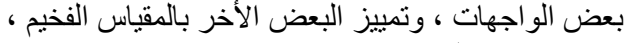

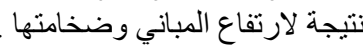

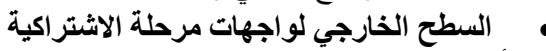

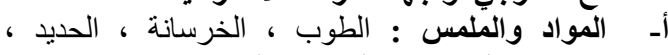

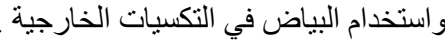

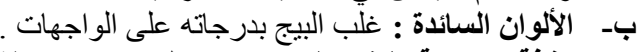

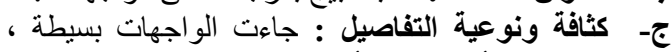

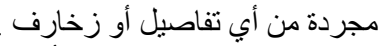

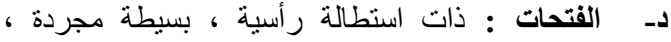

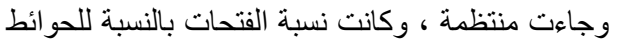

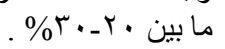

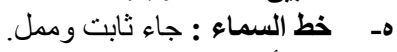

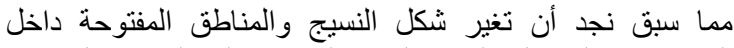

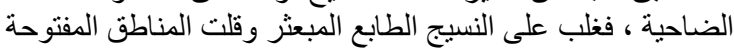

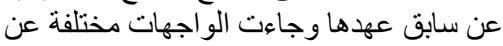

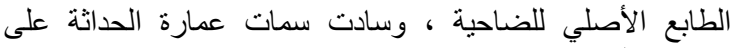

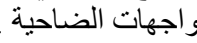

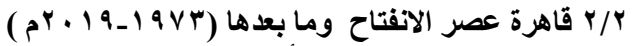

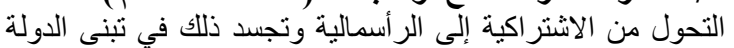

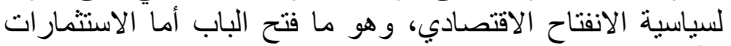

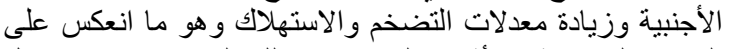

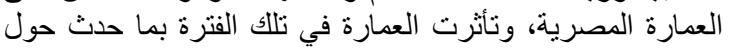

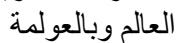
أــ العوامل العولمة المؤثرة على تلك الفترة

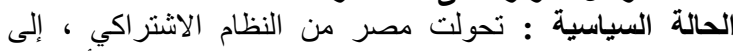

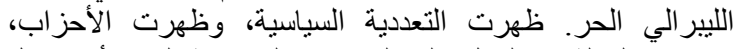

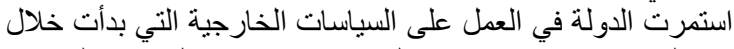

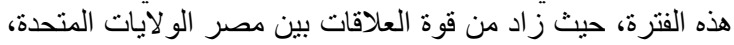

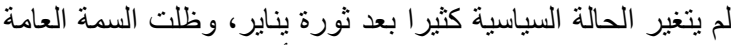

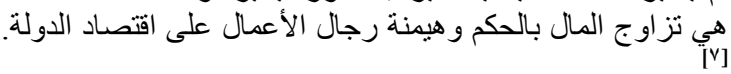

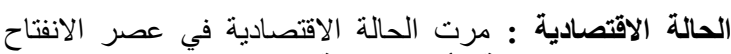

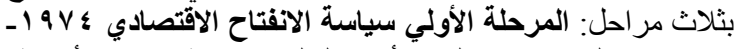

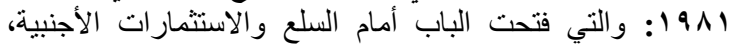

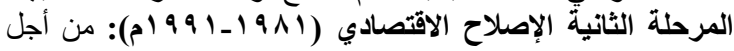

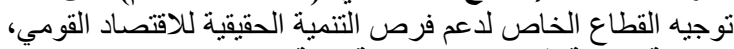

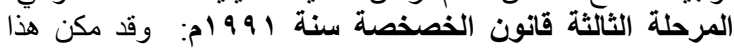

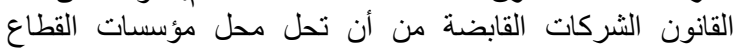

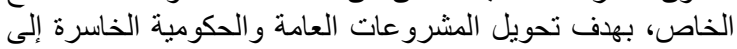

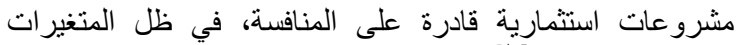

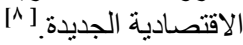

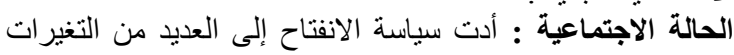

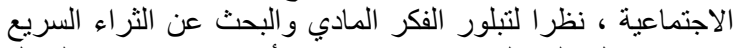

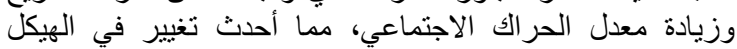

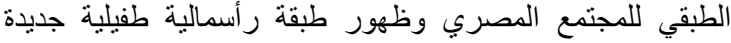

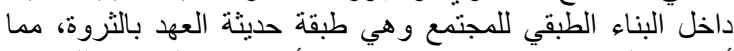

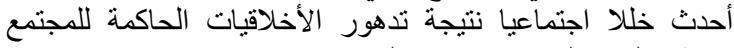

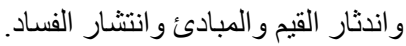


أ.د ـ إيمان محمد عيد عطية، م. شيماء مصطفي حامد "مواجهة تحديات التغريب من خلال أعمال المعماريين الأجاتب في مصر"

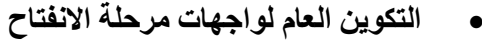

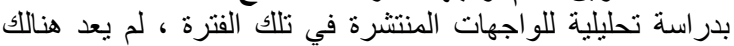

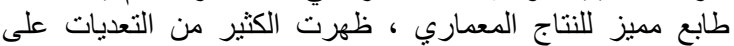

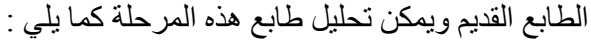

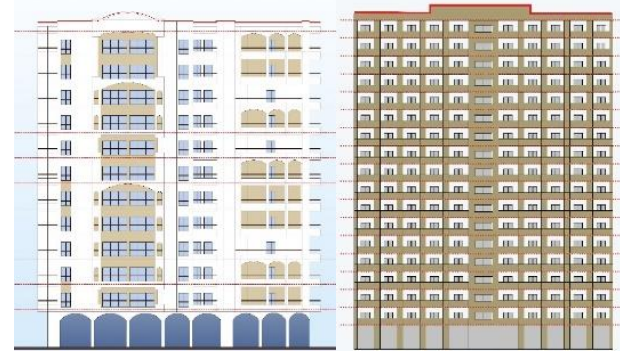

الثكل العام : لم يعد هناك شكل عام موحد ، تعددت

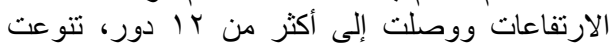

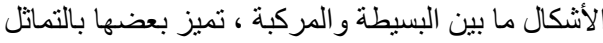

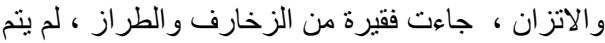

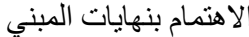
ب- الطراز : ساد الطراز الحزائن الحداثة وما بعد الحداثة وطرز

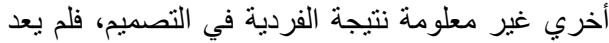

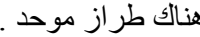
ج- النسب السد إلى المفتوح : تغلبت النسب المغلقة على دـ الخطوط الرأسية والأفقية : تنوعت بين الرأسية و المنحنية . الفطوطية

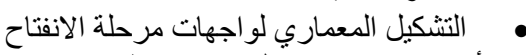

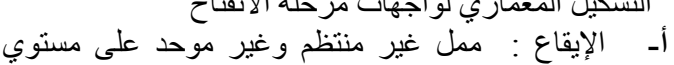

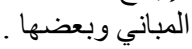

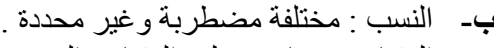

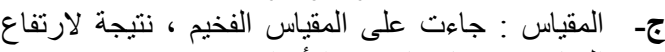

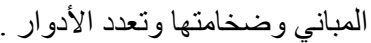

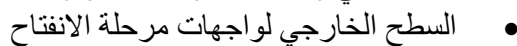

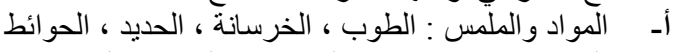

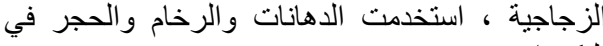

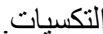
ب- الألوان السائدة : لا نوجد ألوان موحدة .

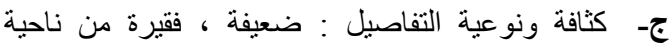

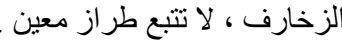

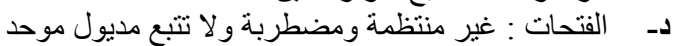

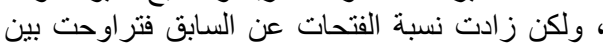

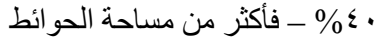

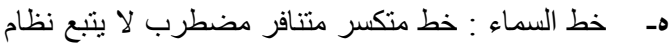

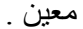

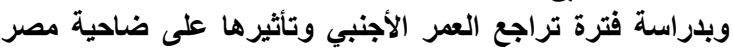

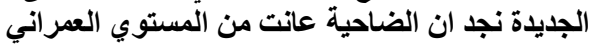

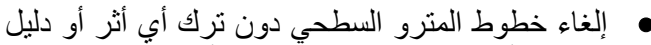

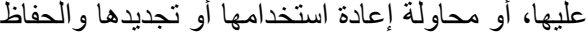

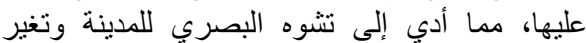

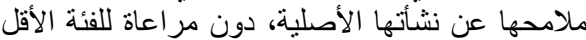

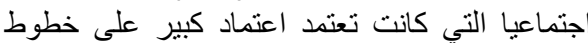
المترو السطحي. تغيرت وظائف كثير من الميادين الأصلية نتيجة تغير

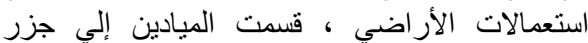
صغيرة ولم تعد لممارسة الأنشطة المرتبطة بها مئ مثل جزي

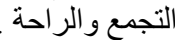
• إنشاء خمس كباري على مستوي الضاحية ترنكز

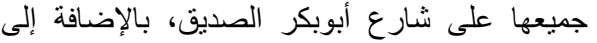
الكباري الموجودة داخل الضاحية و التي لم تثبت نفعها لإنيا

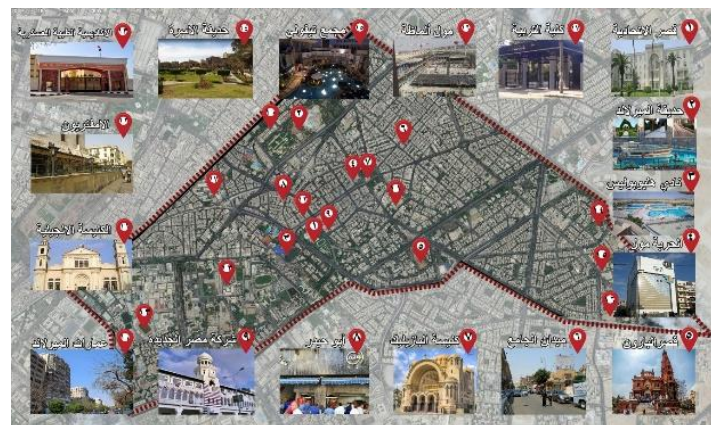

شكل V خر ائط الصورة الذهنية لمرحلة الانفتاح وما بعدها : المصدر : تجميع الباحث

النسيج العمراني والمناطق المفتوحة : كان بداية هذه النها

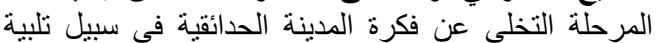

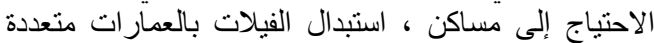

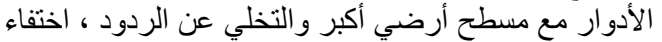

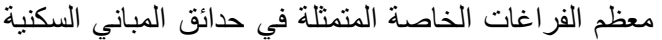

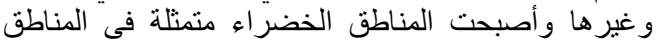

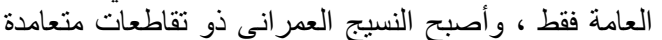

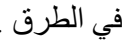

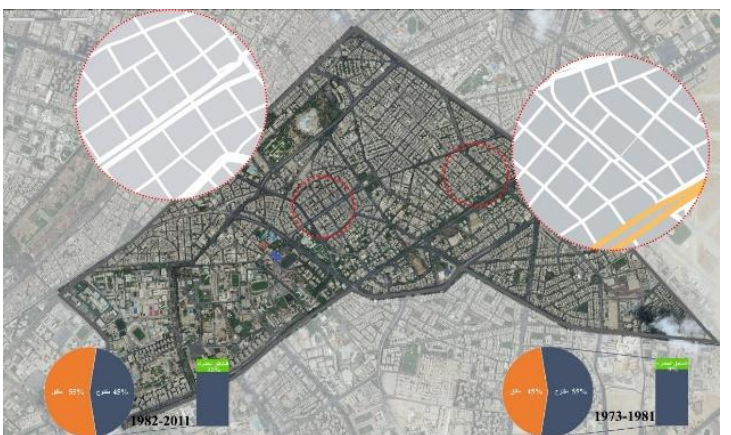

شكل ^ النسيج العمر اني والمناطق المفتوحة المصدر : تجميع الباحث

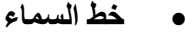

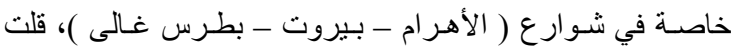

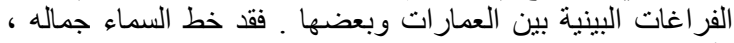

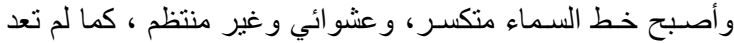

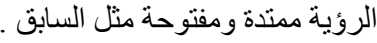

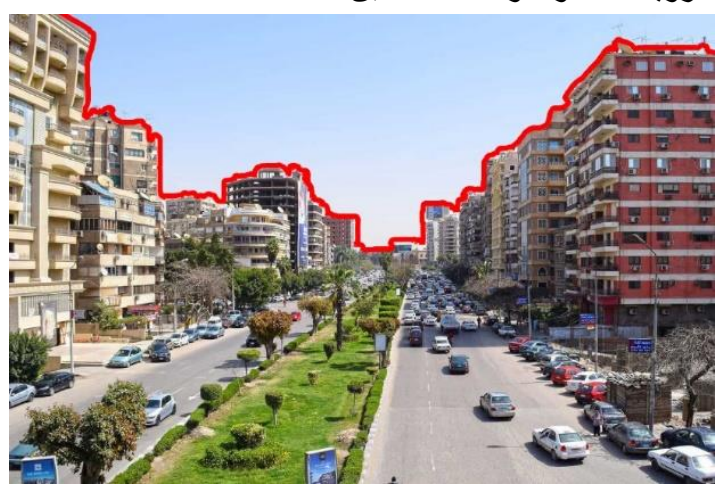

شكل 9 خط السماء لفترة الانفتاح وما بعدها المصدر : www.flicker .com

ج- تحليل الطابع المعماري خلال فترة الانفتاح وما بعدها

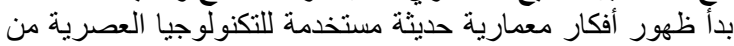

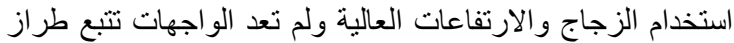

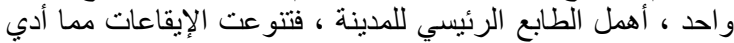

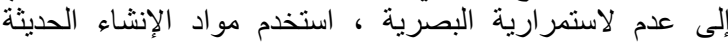
و التقنيات الغربية ، لم تكن هناك اشثتر اطات أو قيود للبناء. 
أ.د. ـ إيمان محمد عيد عطية، م. شيماء مصطفي حامد "مواجهة تحديات التغريب من خلال أعمال المعماريين الأجاتب في مصر"

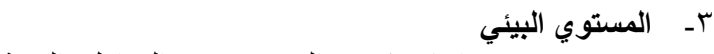

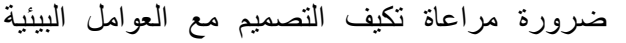

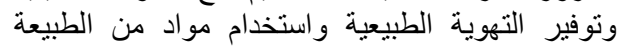

المحيطة . المبرة

إعطاء الأولوية لتنفيذ المسطحات الخضراء المفتوحة

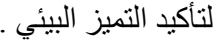

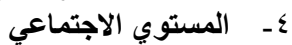

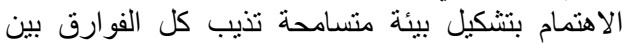
الفئات الدينية أو الفئات الاجنماعية . لأنيات

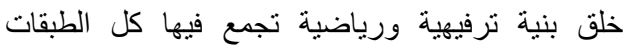
الاجنماعية دون إقصاء لفئة معينة .

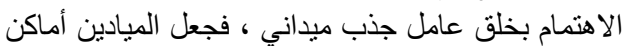

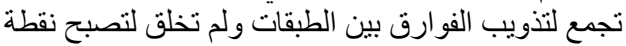

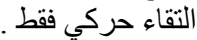

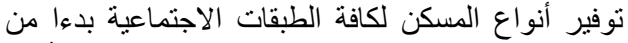

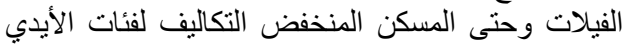
العاملة ، و الربط بينهم بطابع معماري المني النئ r تم تقسيم التوصيات على عدة مر احل : أولا على مستوى المعماريين :

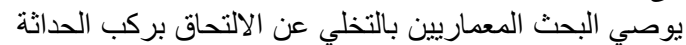

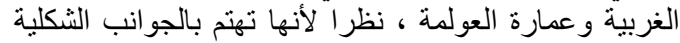

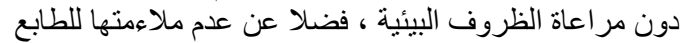
المحلي و الثقافي . يوصي البحث بنطويع التقدم التكنولوجي في مجال العمارة ،

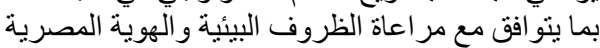

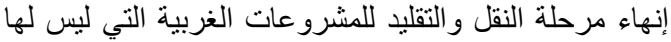

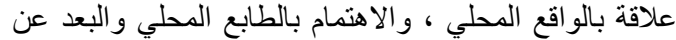

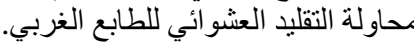

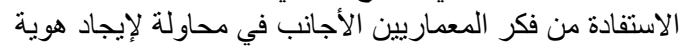

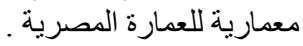

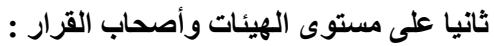

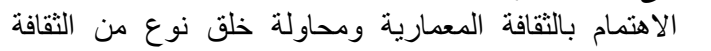
المعمارية لاى المجتمع لتشجيع روح الدمارية الدفاظ على التراث

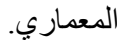

يوصى بتعديل بنود القو انين الخاصة بهدم المباني و المحافظة

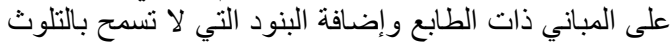
البصري مع تطبيقها.

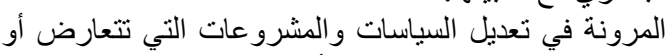

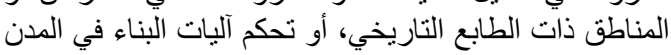

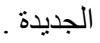
تطبيق القوانين على المخالفات البنائية وخاصة إعادة تأهيل الدباني دون التر اخيص ومر اجعة المن المختصين. إدراج المناطق ذات التراتئ الطابع التاريخي ضمن الهنين أهداف تنمية

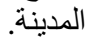

تقييم المشرو عات المنفذة في المناطق ذات الطابع المميز ونشر نتائجه للاستفادة منه وتلافي السلبيات.

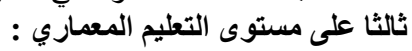

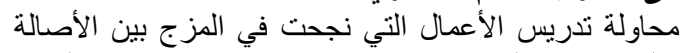

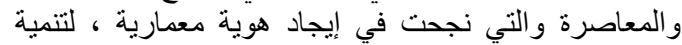

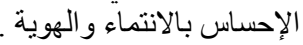

دراسة التجارب الناجحة في تطويع التكنولوجياء التوبيا ، وحققت

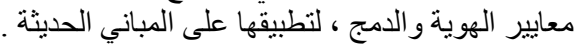
مناقثة القضايا المتعلقة بالهوية ولئية التغريب في المباني المحافل الدولية

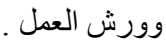
تنمية قدرة المعماريين على النقد المعماري للمباني الفاقدة

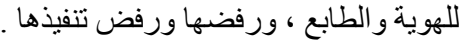

لأنها تصب في نفس المكان (السبع عمار ات) فلم تقوم

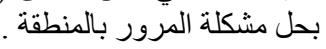

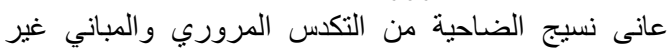

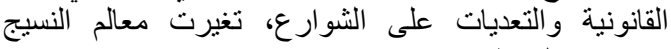

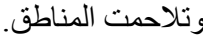

سياسة التصحر التي اجتاحت الضاحية، فنم التعدي على لتى

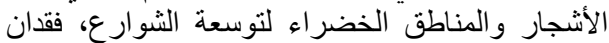

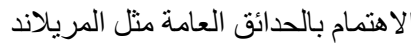

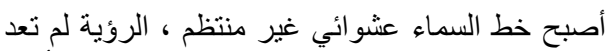

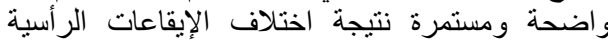

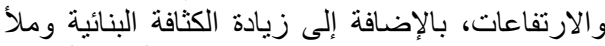

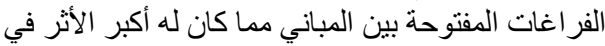

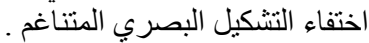
علي المستوي المعماري

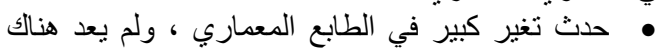

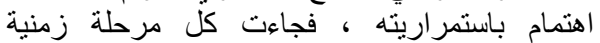

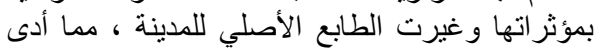

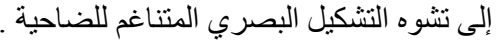

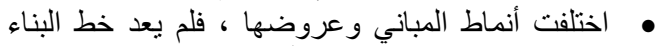

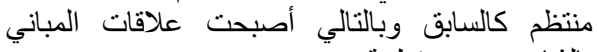
بالثار ع غير منتظمة.

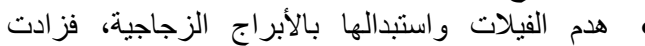

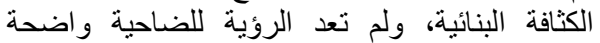

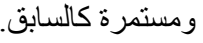
• تحول الكثير من الضاحية لمناطق تجارية، فالدور

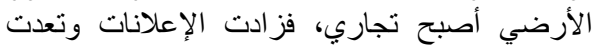

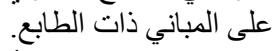
• تغير استخدام معظم الأروقة لاستخدامها من الباعة الباعة الجائلين، فلم تعد تستخدم لغرضنها الأساسي.

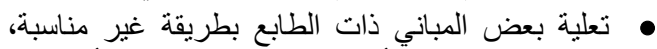

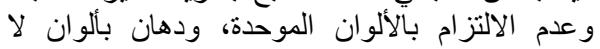
تنتاسق مع القائم.

النتائج والتوصيات النتائج :

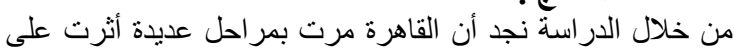

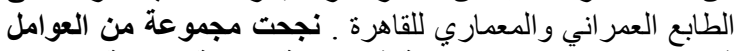

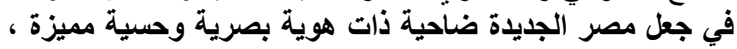

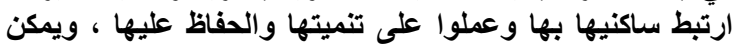

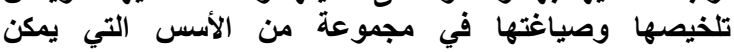
استخدامها الآن للنهوض باغئها في العمارة والعمران :

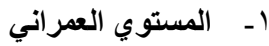

الاهتمام بتكوين صورة بصرينية مميزة كعامل جذب لبن سكاني للز ائرين . الانكوين

الاهتمام بتوفير كافة وسائل الموائن اصلات لجميع الفئات

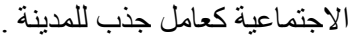

تزويد المجتمع العمر اني بأنشطة متمبزة ومبتكرة لجذب لاعب

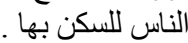

الاهتمام بجعل الرؤية مفتوحة واسعة لزيادة الإحساس

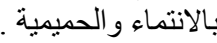
r - المستوي المعماري

توحيد الطابع العام في المنطقة ، وتحديد مواد البناء

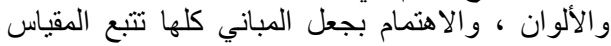

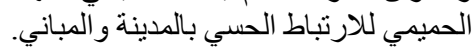

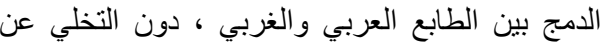

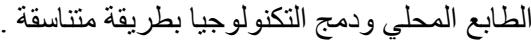

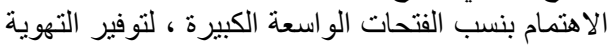
الطبيعية مع الحفاظ على الخصوصية. 
أ.د ـ إيمان محمد عيد عطية، م. شيماء مصطفي حامد "مواجهة تحديات التغريب من خلال أعمال المعماريين الأجانب في مصر"

Lynch, k, The Image of the city, the MIT press, 1960, P49-84.

Moughtin K, Urban Design: Street and square, Butter worth, Heinemann-LTD, P112

Y

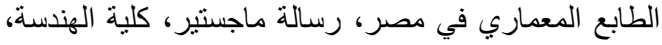

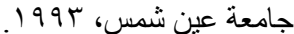

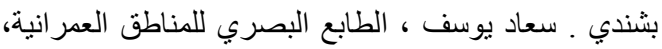

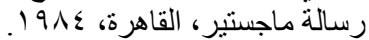

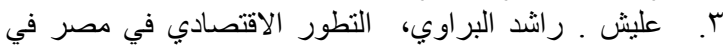

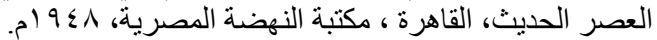

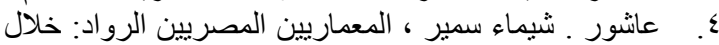

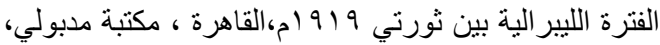

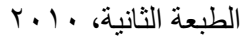

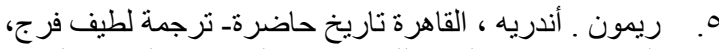

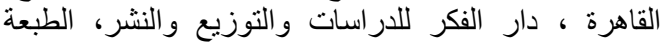

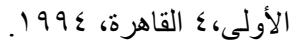

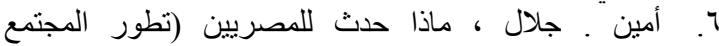

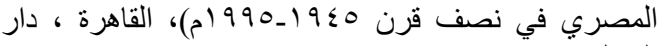

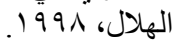

L. Tignor, Robert, Mubarak's Egypt, Princeton university press, 2010

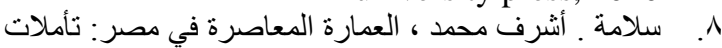

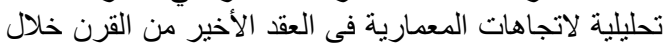

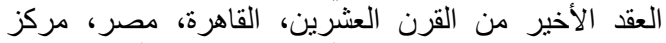
طارق الهناجر للفنون بدار الأوبرا، المجلس الأعلى للثقافة،

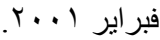

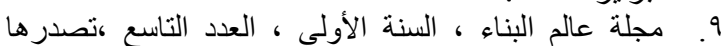

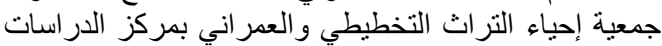

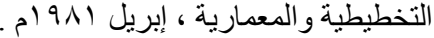

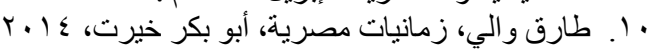

Dobrowolski, Heliopolis Rebirth of the city, .'11 The American University in Cairo Press, Cairo -NewYork,2004. المواقع الإكترونية :

[12] Https://www.faroukmisr.net, in April 2016.

[13] www. cairobserver.com, in March 2016.

[14] www.flicker.com, in May 2019 

أ.د ـ إيمان محد عيد عطية، م. شيماء مصطفي حامد "مواجهة تحديات التغريب من خلال أعمال المعماريين الأجاتب في 